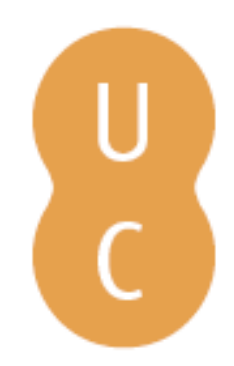

\title{
pommalina
}

\section{Da Idade Média ao Renascimento: percursos gramaticais}

Autor(es): $\quad$ Assunção, Carlos; Santos, Maria Helena

Publicado por: Imprensa da Universidade de Coimbra

URL

persistente:

URI:http://hdl.handle.net/10316.2/38953

DOI:

DOI:http://dx.doi.org/10.14195/978-989-26-0395-7_7

Accessed : $\quad$ 26-Apr-2023 07:14:05

A navegação consulta e descarregamento dos títulos inseridos nas Bibliotecas Digitais UC Digitalis, UC Pombalina e UC Impactum, pressupõem a aceitação plena e sem reservas dos Termos e Condições de Uso destas Bibliotecas Digitais, disponíveis em https://digitalis.uc.pt/pt-pt/termos.

Conforme exposto nos referidos Termos e Condições de Uso, o descarregamento de títulos de acesso restrito requer uma licença válida de autorização devendo o utilizador aceder ao(s) documento(s) a partir de um endereço de IP da instituição detentora da supramencionada licença.

Ao utilizador é apenas permitido o descarregamento para uso pessoal, pelo que o emprego do(s) título(s) descarregado(s) para outro fim, designadamente comercial, carece de autorização do respetivo autor ou editor da obra.

Na medida em que todas as obras da UC Digitalis se encontram protegidas pelo Código do Direito de Autor e Direitos Conexos e demais legislação aplicável, toda a cópia, parcial ou total, deste documento, nos casos em que é legalmente admitida, deverá conter ou fazer-se acompanhar por este aviso. 
Nair de Nazaré Castro Soares

Santiago López Moreda

Coordenação

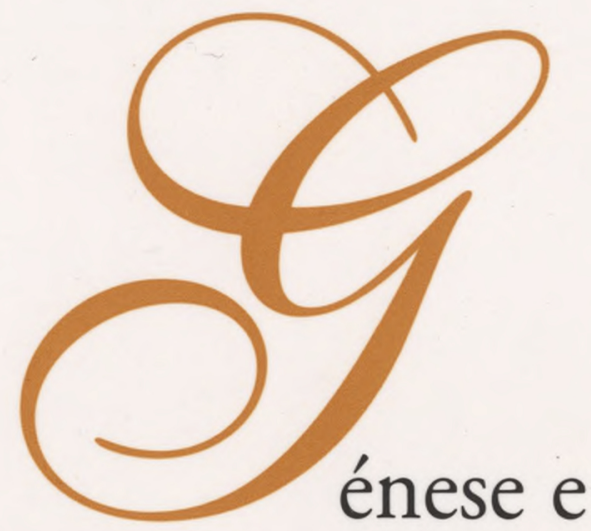

Consolidação da Ideia de Europa

Vol. IV

Idade Média e Renascimento

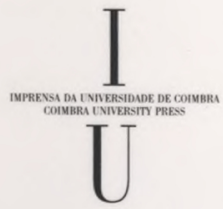

- COIMBra 2009 


\title{
DA IDADE MÉDIA AO RENASCIMENTO: PERCURSOS GRAMATICAIS
}

\author{
CARLOS ASSUNÇÃo \\ MARIA HELENA SANTOS \\ (Universidade de Trás-os-Montes e Alto Douro)
}

No que à Península Ibérica diz respeito, revela-se-nos fundamental o facto de que, ao longo dos séculos IX a XI, período em que já estava em formação a nação portuguesa, são os monges - afinal «os grandes responsáveis pela transmissão do saber antigo», no mundo ocidental (J. Mattoso 1997: 356) - quem garante o ensino e cria escolas, encarregando-se da instrução dos «meninos "oblatos"» (J. Mattoso 1997: 359), através de métodos de ensino muito rudimentares, de que eram suportes livrescos o Saltério, a Ars minor de Donato e as Etimologiae de Isidoro de Sevilha' (cf. J. Mattoso 1997: 364-366),

1 «Começando pela aprendizagem do alfabeto, os mestres ensinavam depois a juntar as letras para formar as sílabas e depois as palavras. Ao mesmo tempo o aluno aprendia a escrever, o que lhe facilitava o conhecimento das letras. Daí passava-se ao estudo do Saltério, livro de leitura que ao mesmo tempo se decorava. [...] Depois de sabida a maior parte do Saltério, aprendia-se a cantar, quer dizer, a apoiar a voz em certas notas e a decorar algumas melodias que serviam de padrão. Finalmente, o ensino elementar compreendia o cálculo com ajuda de pedras e dos dedos. [...] Nos mosteiros em que o abade se interessava pelo progresso intelectual dos oblatos, ia de vez em quando examinar os seus progressos. Noutros, o único responsável pela passagem do oblato a um grau mais elevado dos estudos devia ser o mestre.» (J. Mattoso 1997: 364, 365.) «Na maior parte dos mosteiros [prospectivamente] portugueses dos séculos IX a XI, o ensino devia ficar por aqui, para a maioria dos oblatos. Mas até os [mosteiros] mais pobres precisavam de formar pelo menos um escriba; e este tinha de aperfeiçoar os conhecimentos do latim, para poder utilizar o vocabulário jurídico e escolher as fórmulas ao seu dispor. Nos mosteiros mais evoluídos, em contacto com os nobres, os oblatos deviam passar a um tipo de ensino que poderíamos chamar secundário. Aprendiam então o significado das palavras latinas, possivelmente com noções sobre a etimologia (tal como se compreendia na época), com auxílio da conhecida obra de Sto. Isidoro. Depois começavam o estudo da gramática, servindo-se da Ars minor de Donato ou do seu resumo feito por Sto. Isidoro no livro I das Etimologias. Se o aluno não aprendia de 
tanto mais que o influxo da reforma carolíngia não constituía, ainda, nesse espaço, uma realidade.

Entretanto, estudos linguístico-paleográficos de documentos particulares de fundos conventuais guardados no Arquivo Nacional da Torre do Tombo vieram confirmar a ideia de que já «se escrevia em Português [pelo menos] na segunda metade do século XII» (A. M. Martins 1999: 493), muito embora, nessa altura, em Portugal, o Latim continuasse a ser - como, aliás, em toda a Cristandade -, a língua ensinada ${ }^{2}$ - no nosso caso -, provavelmente, ainda por meio do "Saltério», por via da utilização de compêndios gramaticais dos grammatici antiqui, designadamente, segundo José Mattoso, «o de Prisciano», por meio de «vocabulários como o de Papias» e, no quadro do que já era «tão tradicional entre nós», através de «enciclopédias como a de Isidoro de Sevilha» (J. Mattoso 1985a: 237).

Posteriormente, na centúria de Duzentos, altura em que se confirmam os limites territoriais portugueses, a sul, em 1249, e a leste, até ao final do século ${ }^{3}$,

cor o próprio texto, devia pelo menos fixar de memória os exemplos ilustrativos das diversas regras.» (J. Mattoso 1997: 365.) «Não temos a certeza de se usarem entre nós os glossários que permitiam enriquecer o vocabulário do professor; mas na sua falta o livro de Sto. Isidoro voltava a servir de recurso, com os seus numerosos vocábulos e as respectivas significações etimológicas, sobretudo no livro X. Finalmente, o oblato aprendia alguma coisa de prosódia, mais para saber conhecer os acentos e as pausas, do que para compor poesias.) (J. Mattoso 1997: $365-366$.

${ }^{2}$ A título de curiosidade, parece-nos interessante trazer a lume um dado mencionado por José Mattoso, a partir da narrativa hagiográfica Vita Sanctae Seniorinae, provavelmente escrita no final do século XII, que aquele insigne historiador considera «deve[r] ser empregada para estudar a espiritualidade e os costumes das monjas beneditinas no fim do século XII, ou princípios do seguinte» (J. Mattoso 1997: 375): embora a sua formação espiritual, de carácter, fundamentalmente, mnemónico, fosse sustentada, por exemplo, nos escritos de St. Ambrósio, na Regra de $\mathrm{S}$. Bento e no costumeiro monástico, «não se deduz claramente que soubessem ler latim» (J. Mattoso 1997: 375-376), «[p]arece[ndo] até que as Vidas dos Santos lhes eram lidas em português» (J. Mattoso 1997: 376).

${ }^{3}$ Em conformidade com José Mattoso, se «a noção de identidade nacional, isto é a diferenciação do regnum como unidade política definida por um poder monárquico sobre um território limitado e os seus habitantes, parece precoce e suficientemente clara desde a primeira metade do século XIII» (J. Mattoso 1985b: II, 211), a consciência da existência de uma nação existe, então, «apenas na mente de uma minoria, geralmente próxima do poder político» (J. Mattoso 1985b: II, 212), de que se destacam os clérigos, mais concretamente, os Cónegos Regrantes de Coimbra, «que produziram várias obras de suporte ideológico ao seu protector Afonso Henriques e de exaltação e propaganda à Guerra Santa, provavelmente por ocasião das invasões almóadas, para encorajarem os Portugueses à resistência" (Mattoso 1995: 206), tendo-se distinguido na criação de uma elite intelectual directamente ligada ao aparelho do Estado. Com efeito, não podemos esquecer-nos de que, em 1131, se iniciara, em Coimbra, com a fundação do Mosteiro de Santa Cruz, um novo movimento religioso, o dos 
inicia-se a época áurea do trovadorismo português, no reinado de D. Afonso III (1245-1279) e no reinado de D. Dinis (1279-1325), no âmbito do qual, aliás, a língua portuguesa «passa a ser a língua oficial do reino[,] em detrimento do latim» (R. V. M. e Silva 1989: 24), nascendo, então, a historiografia em Português. É, ainda, no século XIII que se incrementa o uso do vernáculo na documentação jurídica real e privada e se procede, significativamente, à fundação da Universidade (1288), que «deve ter acompanhado, com algum atraso, a intensificação dos estudos gramaticais [da língua latina], já então geralmente praticados, em Portugal, nas escolas monásticas e capitulares» ${ }^{4}$ (T. Verdelho 1995: 32). Ademais, parece que é também nessa época que se dá início à produção literária em prosa e que, no final da centúria, se fazem já, pelo menos no mosteiro de Alcobaça, traduções, para o Português, de textos latinos de cariz religioso $^{5}$ (cf. R. V. M. e Silva 1989: 21-22, 26, 27, 32).

Cónegos Regrantes de St. Agostinho, «iniciativa autóctone» (J. Mattoso 1985a: 210) de D. Telo, que viajara por Jerusalém, Constantinopla, Pisa e Avinhão, S. Teotónio, que viajara pela Terra Santa, e D. João Peculiar, que se formara em França (cf. J. Mattoso 1985a: 112). Ao mesmo tempo que defendiam os direitos das comunidades de moçárabes ainda existentes, as quais, até cerca de 1116 , tinham, nessa região, resistido à integração da liturgia e obediência romanas (cf. J. Mattoso 1985a: 211), os Cónegos Regrantes pretendiam «afirmar a sua completa ortodoxia, pela adopção de costumes monásticos praticados em $\mathrm{S}$. Rufo de Avinhão (cujas ligações mediterrânicas são significativas) e por terem desde muito cedo procurado a isenção canónica, pondo-se sob a protecção da Santa Sé» (J. Mattoso 1985a: 211). Esse movimento religioso constituiu, sem dúvida, o apoio espiritual da monarquia que então nascia, tanto mais que, em 1132, o centro da corte foi deslocado, por D. Afonso Henriques, para Coimbra. Foi no Mosteiro de Santa Cruz que D. Afonso Henriques veio a guardar o seu tesouro e os documentos da sua chancelaria e ai foi buscar os seus mais activos diplomatas, precisamente, D. João Peculiar e D. Telo. Foi, ainda, através dos Cónegos Regrantes, organizados em função de uma obra pastoral desenvolvida no meio das classes vilãs da cidade $\mathrm{e}$ das regiões fronteiriças, que $\mathrm{D}$. Afonso Henriques entrou em contacto com as camadas então ditas inferiores da população.

${ }^{4}$ São os mosteiros de Santa Cruz de Coimbra e de Alcobaça, quais centros intelectuais, aparecidos, no século XII, e algumas escolas capitulares que «estabelecem a ligação com a cultura escolástica que a fundação da Universidade dionisiana assegura e promove a partir de 1288" (J. Mattoso 1997: 356). José Leite de Vasconcelos observa que, «antes da fundação da Universidade portuguesa[,] havia em diversas catedrais e igrejas paroquiais do reino, ao lado de livrarias franqueadas ao público, aulas de Gramática» (J. L.Vasconcelos 1929: 860), que também se ensinava em alguns mosteiros, nomeadamente, no de Santa Cruz de Coimbra e no de Alcobaça (cf. J. L.Vasconcelos 1929: 860). Este eminente estudioso indica, ademais, que, no ano de 1269 , se funda, no mosteiro de Alcobaça, «um estudo de letras (Gramática, Lógica, e Teologia)» (J. L.Vasconcelos 1929: 860-861), ao que parece instituido pelo abade D. Fr. Estêvão Martins (cf. J. L.Vasconcelos 1929: 861).

${ }^{5}$ São os monges da Ordem religiosa de Císter, corrente monástica implantada, em Portugal, a partir dos anos Quarenta do século XII, no final do qual desempenham já um papel importante junto do rei e da nobreza de corte (cf. J. Mattoso 1985a: 119, 253-254), 
Quanto à produção gramatical portuguesa medieval, cumpre dizer que a única gramática que, na Idade Média, foi, aparentemente de forma anónima, escrita em Português versa sobre o Latim, data, segundo se conhece, do século XIV e constitui, portanto, o primeiro texto escrito em Português em que se reflecte sobre uma língua, nele se propondo, «pela primeira vez, o aportuguesamento sistemático de toda a terminologia gramatical» (T. Verdelho 1995: 45).

No restante mundo ocidental, depois de 1300, os gramáticos nominalistas e os averroistas latinos lançam diversos ataques à metateoria modista ${ }^{6}$, progressivamente reduzida, a partir de então, a uma condição de inércia, não obstante se verifique que os gramáticos humanistas não abandonam completamente esse modelo $^{7}$ (cf. M. A. Covington, 1992: 151, col. 2; G. L. Bursill-Hall, 1994: 2233, col. 1-2).

que, visando a moralização da função dos cavaleiros que professavam nas ordens militares, os quais exortavam à abnegação e à renúncia, «traduz[e]m para português a narrativa da viagem de Túndalo aos infernos, onde a visão das penas eternas ameaça constantemente o cavaleiro com a consciência atormentada pelas suas numerosas faltas» (J. Mattoso 1985a: 119). Preocupando-se com a humanização e personalização do sentimento religioso da sua clientela profana, "ainda mergulhada num[a] religiosidade profundamente mitica» (J. Mattoso 1985a: 119), S. Bernardo e os seus discípulos ordenam a tradução para português de obras de cariz religioso «que difundem estes temas e expressões sentimentais, embora postas a correr sob nomes prestigiosos como Santo Agostinho [ - Solilóquios, de PseudoAgostinho - ] e o próprio S. Bernardo [ - Meditações, de Pseudo-Bernardo]» (J. Mattoso 1985a: 119). «Mais tarde são também traduzidas em português outras obras que fazem uso dos mesmos recursos [da emotividade], num contexto de ficção já influenciada pelos romances, como acontece com a obra anónima do Horto do Esposo, e com a de um Cartuxo, intitulada Castelo Perigoso.» (J. Mattoso 1985a: 119.) Curiosamente, parece provável que as obras traduzidas pelos Cistercienses se destinassem, sobretudo, aos seus conversos, "camponeses desenraizados que procuravam as terras do Centro e do Sul para poderem subsistir» (J. Mattoso 1985a: 120) e cuja força de trabalho os Cistercienses rentabilizavam, constituindo-os em «grupos preocupados com a perfeição espiritual e interessados nas realidades divinas, embora pouco conhecedores da teologia escolástica» (J. Mattoso 1985a: 120).

${ }^{6}$ Eis alguns dos argumentos apresentados contra os modi significandi, a partir do relato efectuado, em 1333, por Johannes Aurifaber: «Modes of signifying are not attributes of the vox significativa 'linguistic sign' because the sign is itself a relation of sound to meaning, not an entity per se, and hence cannot have attributes.» "If linguistic signs are arbitrary, so are their modes of signifying; hence they are not proper objects for scientific study.» «Modes of signifying are not needed to distinguish the parts of speech; logicians distinguish them on the basis of meaning alone.» (M. A. Covington 1992: 151, col. 2.)

${ }^{7}$ Afirma W. Keith Percival que, «throughout the fifteenth and well into the sixteenth century, medieval grammatical works continued to be transcribed and printed, and hence [...] widely used». (W. K.Percival 1975: 239). «Modistic grammars, for example, were still being reprinted in the sixteenth century and modistic concepts are clearly discernible in some philosophical discussions of language, as for example in the important De veris princi- 
A verdade é que «[t]he early Renaissance humanists, notably Petrarch (1304-1374) and Coluccio Salutati (1331-1406), despite their disdain for many aspects of scholasticism, [are] content to use the grammatical literature available in their day» (W. K. Percival, 1994: 3540, col. 2), designadamente, a obra, de 1099, Doctrinale, de A. Villa-Dei, e a obra Graecismus, de Eberhardus Bethuniensis, localizável cerca do início do século XII, a Ars minor, de Donato, e Ianua sum rudibus primam cupientibus artem, incipit de uma compilação anónima de raiz prisciânica (cf. W. K. Percival, 1975: 238), reduzindo, porém, a gramática «to its original propaedeutic function as the most basic of the liberal arts, the gateway to knowledge, and the indispensable tool for the study of the revered classical authors» (W. K. Percival, 1994: 3540, col. 2).

Cumpre salientar, a propósito, que se regista, no primeiro quartel do século XIV, uma tendência para se produzirem textos de grammatica positiva, ou gramática normativa, não sob a forma de súmulas, como sucedera anteriormente, mas sob a forma de tratados «plus ciblés et plus nombreaux» (A. Grondeux, 2000: 608), «consacrés aux verbes impersonels, aux figures de syntaxe, aux comparatifs et superlatifs, et aux conjonctions, inspirés de façon mixte de traités modistes comme ceux de Martin de Dacie ou Simon de Dacie, comme de textes de grammaire normative, Doctrinale et Graecismus" (A. Grondeux, 2000: 608). Veja-se, aliás, que, então, os manuais representativos da grammatica positiva, Doctrinale e Graecismus, são mesmo recomendados pelos estatutos universitários europeus, que, até aí, haviam consignado, apenas, o estudo de Priscianus maior, de Priscianus minor e de De barbarismo de Donato. Interessantemente, é àquelas duas últimas obras inspiradoras dos supra-referidos tratados, especialmente à obra de Villa-Dei, bem como à anónima Ianua sum rudibus primam cupientibus artem, que se recorrerá, no século XV, para se aprender o Latim, embora os humanista italianos comecem, então, a elaborar, eles próprios, obras gramaticais (cf. B. Colombat 2000: 661-662). Digno de nota é o facto de que os estatutos das Universidades de Viena (1389) e de Friburgo (1460-1490), por exemplo, "semblent en effet [...] préconiser, outre le Donat mineur, l'enseignement des deux ou des trois premières parties du Doctrinale et de la secunda pars Graecismi, et non plus des manuels dans leur

pis et vera ratione philosophandi contra pseudophilosophos by Mario Nizzoli (Parma, 1553 $[\ldots]) .[\ldots]$ In Spain and Portugal the pre-humanistic grammar of Juan Pastrana (the Compendium grammatice) was still popular in the sixtennth century in spite of the impact of the works of the humanist Antonio de Nebrija. In Italy and Germany the Catholicon of John of Genoa was printed a number of times in the incunabular period. We also know from statements of Sánchez de las Brozas that medieval grammar and logic persisted at the University of Salamanca until well into the sixteenth century [...].» (W.K.Percival 1975: 239-240.) 
ensemble», "sans que l'on puisse savoir si cette précision entérine un usage général, ou si la suppression des chapitres en question doit être tenue pour une innovation pédagogique contemporaine» (A. Grondeux 2000: 607). A verdade é que a gramática reassume o seu humilde estatuto de "foundation stone in the edifice of the belles lettres» ${ }^{8}$ (W. K. Percival 1994: 3540, col. 2), sendo pouco clara a fronteira entre grammatica positiva (gramática normativa) e grammatica speculativa.

O primeiro tratado gramatical humanista parece dever-se, precisamente, a Guarino Veronese (1370-1460), tomando forma, «some time before 1418» (W. K. Percival 1975: 238), sob o título de Regulae grammaticales. Ao pretender fornecer material suficiente para a aprendizagem da leitura e da escrita correctas da língua latina, Guarino Veronese inclui, nesta obra, «a tightly organized syntax in the style of Guarino's fourteenth-century predecessors and a series of short chapters on a variety of topics (irregular noun inflection, comparatives, relative pronouns, syntactic figures, etc.)» (W. K. Percival 1994: 3540, col. 2-3541, col. 1), procurando, até certo ponto, «motivated chiefly by considerations of pedagogical effectiveness rather than by any deep-seated theoretical misgivings» ${ }^{9}$ (W. K. Percival, 1975: 245), expurgar da teoria gramatical conceitos denunciadores da ligação que, antes, se havia estabelecido entre lógica e gramática $^{10}$ (cf. W. K. Percival 1975: 239).

Entretanto, as descobertas progressivas, que se vinham fazendo, desde o princípio do século $\mathrm{XV}$, de manuscritos de obras gramaticais de autores latinos, que não Donato ou Prisciano, com que os gramáticos medievais haviam

${ }^{8}$ Segundo W. Keith Percival, «what they attempted to do was to acquire not merely superficial grammatical correctness but also something of the genuine style of the Roman writers of the classical period, a quality which they referred to as elegantia») (W.K.Percival 1994: 3540, col. 2).

${ }^{9}$ Conforme continua a apontar Percival, embora se proceda à excisão de partes nãodesejadas da tradição medieval, «little in the way of original or novel concepts was introduced at this time» (W.K.Percival 1975: 245).

${ }^{10}$ "The humanists wanted to conquer new territories for their subjects - grammar, rhetoric, poetics, history, moral philosophy [, studia humanitatis que não correspondiam às artes do trivium, ] - in the universities [...], as well as in the chancelleries and in the princely courts, those centres where they had first laid their roots; and they did so in an aggressive fashion, with attacks in their writings on the medieval teaching of grammar - both positive grammar and speculative grammar - of dialectic and of natural philosophy which were quite violent.» (M.Tavoni 2000: 654-655.) Na verdade, «while traditional university pedagogy conceives of grammar as functional to dialectic, humanist pedagogy views grammar as functional to rhetoric» (M.Tavoni 2000: 652). No entanto, apesar desses ataques violentos, reivindicativos da autoridade da Antiguidade, «leurs analyses restent le plus souvent inscrites dans le moule traditionnel» (B.Colombat 2000: 662). 
estado familiarizados, estimulam a re-avaliação humanística da gramática tradicional. Lorenzo Valla ${ }^{11}$ (1406-1457), pretendendo «donner du latin [clássico] une description aussi précise que possible, à la fois pour l'emploi des formes et leur construction» (B. Colombat 2000: 662), compõe, entre 1430 e 1449, Elegantiarum linguae Latinae libri sex ${ }^{12}$, no âmbito dos quais «pour[s] scorn on the Graecismus» (W. K. Percival 1975: 240), e redige «a short treatise pointing out [e corrigindo] certain mistakes in the Doctrinale» (W. K. Percival 1975: 240). Adicionalmente, depois de, perto do final da primeira metade do século $\mathrm{XV}^{13}$, Leon Battista Alberti (1404-1472) haver escrito "a grammatical sketch of Italian» (W. K. Percival 1994: 3542, col. 1) - que só se tornou amplamente conhecido, ainda sob forma manuscrita, no final do século XIX, nele defendendo o autor o uso preferente do vernáculo, em detrimento do Latim, por o considerar «a more universal medium of communication than Latin in not being confined to the learned» (W. K. Percival 1994: 3542, col. 1-2) e "capable of being as expressive as Latin» (W. K. Percival 1994: 3542, col. 2), como já haviam demonstrado Dante Alighieri ${ }^{14}(1265-1321)$, Giovanni Boccaccio (1313-1375) e Petrarca (1304-1374), os três primeiros autores a fazerem, em

"Embora não seja tarefa fácil dar conta da recepção que a obra de Lorenzo Valla teve, em Portugal, nos séculos XVI e seguintes, é digno de destaque o facto de ser citado, em gramáticas quinhentistas portuguesas do Latim, nomeadamente, por Estêvão Cavaleiro, Máximo de Sousa, André de Resende, Jerónimo Cardoso e Fernando Soares Homem, sendo, ainda, significativa a especial referência que o Infante D. Duarte lhe dedica no âmbito da sua Oração em louvor da Filosofia, proferida no Colégio da Costa, antes de Novembro de 1543: "Entre hos Grammaticos Nebrissente [sic] dos Espanhoes mais docto, Prisciliano [sic] nom menos antigo que elegante, Diomedes, Donato, Sérvio, Linacro, Peroto, e os mais que nesta arte floreceram se devem de ler. Esqueciame Lourenço de Valla o qual diante de todos ouvera de nomear o qual nom sey se recebeo tanta honrra das Musas em sua singular eloquencia quanta lhe fez em deterrar [sic] a barbaria e restituir o Latim a seu antigo primor homem doctissimo em Grego e em latim, e que honrrou as Musas com sua agudeza." (In A. M. Sá 1982: 201. As sérias dúvidas assinaladas na lição filológica deste texto, precariamente transmitido por A. Caetano de Sousa, não prejudicam o nosso propósito.)

${ }^{12}$ Essa obra «is lexicographical and phraseological in character: it is chiefly a collection of words, locutions, and syntactic constructions, backed up by examples from the classical authors» (W.K.Percival 1994: 3540, col. 2). «Valla presents no systematic grammatical apparatus and no system of syntactic analysis, confining his attention to those aspects of style which can be discussed in connection with isolated words» (W.K.Percival 1994: 3540, col. 2).

${ }^{13}$ W. Keith Percival aponta, como data provável, o final da década de Quarenta (cf. Percival 1994: 3542, col. 1) e B. Ricardson situa a composição da obra em 1437-1441 (cf. B. Richardson 1994: 3246, col. 2).

${ }_{14}$ La Divina Commedia foi escrita em dialecto toscano, ousadia que valeu a Dante Alighieri acerbas críticas de latinistas inconformados com tal atitude revolucionária. 
Itália, uso literário do vernáculo -, Niccolò Perotti (1429-1480), em 1468, elabora "[t] he first complete Latin grammar in the humanistic style» (W. K. Percival 1975: 238), ou «the first comprehensive grammar and stylistics of Latin» (W. K. Percival, 1994: 3541, col. 1), publicada em 1473, Rudimenta grammatices, cuja segunda parte ${ }^{15}$, sobre sintaxe, expande a secção relativa à sintaxe da obra de Guarino Veronese ${ }^{16}$ (cf. W. K. Percival 1994: 3541, col. 1).

Tal como sugere Keith Percival, «[foram] relevantes para a teoria gramatical renascentista certas correntes da tradição gramatical na Europa meridional (neste caso, a Provença e o norte da Itália) que coexistiram em parte com o desenvolvimento da gramática modista na Alemanha e no norte de França», tendo sido essa "versão meridional da tradição gramatical ocidental que, ao florescer nos séculos XIII e XIV, forneceu fundamentação teórica às produções gramaticais humanistas do século XV» (Percival apud M. S. Barreto 1988: 166 - a tradução portuguesa é da responsabilidade de Barreto). Daí que a gramática pareça, com efeito, perder alguns dos elementos herdados dos Modistas. Por um lado, os termos do aparelho metalinguístico sofrem uma redução, vendo-se a diassintáctica objecto de excisões sucessivas até quase se reencontrar com a sintaxe prisciânica e, consequentemente, com o modelo que Prisciano confessadamente quis imitar, a saber, a Peri sintaxeos de Apolónio Díscolo, e anulam-se os excursos em que cabiam as controvérsias sobre questões de método e de coesão na arte de interpretar e de representar a realidade. Por outro lado, a gramática deixa de ser apenas a ars que os escolásticos gostavam de definir como plurium praeceptorum collectio ad unum finem tendentium (A. Scaglione 1970: 25), dirigida ao professor e destinada à «preparação de futuros professores» (A. Scaglione 1970: 26), para passar a ser encarada como meio didáctico no âmbito de uma pedagogia que considerava o aprendente «mais como futuro cidadão do que futuro professor ou académico profissional» (A. Scaglione 1970: 26).

Curiosamente, as supramencionadas obras de Guarino Veronese e de Niccolò Perotti, a saber, Regulae grammaticales e Rudimenta grammatices,

${ }^{15}$ A primeira e a terceira partes dessa gramática são dedicadas a «an elementary morphology» e a "a treatise on epistolary composition» (W.K.Percival 1975: 238).

${ }_{16}$ «La première partie de ces ouvrages traite des parties du discours et de leurs 'accidents' (les catégories qui les affectent), [...] en suivant de préférence l'ordre d'exposition et les définitions données par Priscien. La morphologie est essentiellement présentée sous la forme de règles de formation [...] pour l'apprentissage du genre et des déclinaisons du nom et la formation des prétérits et supins des verbes. La syntaxe, fondée sur l'opposition entre accord et régime, est pour la grande part consacrée à la construction des verbes [...]. Elle est complétée par un exposé sur les huit figures de construction qui traitent principalement des accords complexes [...].» (B. Colombat 2000: 662.) 
respectivamente, constituirão, no final do século $\mathrm{XV}$, os grandes motores da renovação gramatical em Portugal. Na verdade, se a designação "mestre de grammatica nova" 17 surge já em 1442 , em documento notarial referido por António Martins, Beja, a expressão "grammatica nova" volta a aparecer a propósito da aquisição, por $\mathrm{D}$. Afonso $\mathrm{V}$, de "dous livros de grammatica darte nova" ${ }^{2}$, em 1449, e de "hum livro de grammatica nova" ${ }^{\text {, }}$, em 1450.

Nove anos depois de ter vindo a lume uma das primeiras sistematizações de uma língua "vulgar", a saber, a Grammatica de la lengua castellana ${ }^{20}$, de Elio Antonio de Nebrija (1444-1522), o português João Vaz, na senda de Guarino Veronese e Niccolò Perotti, dá voz à defesa da codificação da língua materna, nos seus In grammaticae rudimentis comentarii, em cuja introdução afirma o seguinte: «decidi empreender tal tarefa [a composição dos comentarii] depois de reflectir sobre o imenso trabalho a que, hoje em dia, são os nossos estudantes sujeitos sem que por isso sejam guiados ao longo daqueles caminhos que rapidamente conduzem à larga via de onde os atalhos se avistam» (J. Vaz 1501: fólio a 1). De forma interessante, aparecem, também, a nível da literatura, algumas manifestações contra o predomínio da cultura latina. Por exemplo, D. Duarte, no Leal Conselheiro, recomenda "grande cuidado e parcimónia na adopção de palavras da língua latina», apresentando-se, assim, no acertado dizer de Agostinho de Campos, "como o mais antigo defensor da vernaculidade e o mais antigo paladino da nossa linguagem» (A. Campos apud Sampaio et alii 1929: 338). Facto é que D. Duarte inclui na supra-referida obra um capítulo - "Da maneira pera bem tornar algũa leytura em nossa lynguagem" - em que resume algumas regras de tradução, de entre elas se destacando a fidelidade ao texto, a utilização de palavras estritamente portuguesas, não

${ }^{17}$ Cf. A. Moreira de Sá (1970), Chartularium Universitatis Portugalensis, vol. IV. Lisboa, p. 347-348, citado por M.S. Barreto 1988: 169.

${ }^{18}$ Cf. ANTT, Leitura Nova, Extras, "Quitação a Gonçalo Eanes tesoureiro das iffantes dona Catarina e dona Ioana [...]" cujo treslado tem início no Fólio LXII v, col. 1. A passagem citada figura no fólio LXIII, col. 1, linhas 8-9.

${ }^{19}$ Cf. ANTT, Leitura Nova, Extras, "Quitação a Gonçalo Eanes tesoureiro das iffantes dona Catarina e dona Ioana [...]" cujo treslado tem início no fólio LXII v , col. 1. A passagem citada encontra-se nos fólios LXIV-V, col. 1, linhas 30-31.

${ }^{20}$ Elio Antonio de Nebrija refez, com originalidade, a divisão clássica das 'partes do discurso': aumenta-as para dez - nome, pronome, artigo, verbo, participio, gerúndio, nome participial infinito, preposição, advérbio, conjunção -, repondo a interjeição no quadro dos advérbios e justificando eruditamente porque se afastara da tradição latina. Destacamos, em relação à obra em causa, a edição feita em dois volumes, no ano de 1946, em Madrid, por Pascual Galindo Romeo \& Luís Ortiz Muñoz. 
alatinadas, o respeito pelo decoro, a clareza, a elegância e a concisão (cf. J. L. Vasconcelos 1929: 863).

Só, porém, em 1536 vem a lume a primeira edição da Grammatica da lingoagem portuguesa, da lavra de Fernão de Oliveira, o primeiro gramático da lusofonia ${ }^{21}$, que se adianta, assim, a Pierre la Ramée (Petrus Ramus), autor de Gramere (1562): «A gramática de Fernão de Oliveira (1536) foi a primeira que se publicou em português; foi a primeira que se publicou do português e de um português; foi a primeira que se publicou do Português e em Portugal» (R. S. Nogueira 1933: 7).

Incompleta e um tanto assistemática, a Grammatica da lingoagem portuguesa apresenta-se dividida em três partes. Da primeira parte - a mais desenvolvida - constam informações de carácter fonético e ortográfico que não se podem desprezar, designadamente, sobre a articulação das vogais e consoantes, precisada com aproximações ao castelhano, latim, grego, hebraico e árabe, sobre a divergência existente entre a prolação dos sons e a sua imagem grafemática, sobre centro silábico e ditongos, sobre normas de acentuação, sobre ortografia, sobre dinâmica linguística e sobre o cuidado a observar na recepção e adaptação de estrangeirismos (cf. A. R. Torres 1998: 53; cf. F. de Oliveira 2000: 19). No âmbito da segunda parte, dedicada ao que, séculos mais tarde, viria a ser designado por morfologia, Fernão de Oliveira estuda as palavras, ou dicções, primitivas, compostas, derivadas, os arcaísmos e neologismos, o valor semântico dos prefixos, as flexões nominais e verbais, bem como a evolução semântica dos vocábulos (A. R. Torres 1998: 53; cf. F. de Oliveira 2000: 19). Por seu turno, a sintaxe - terceira parte da referida obra - sofre um parco desenvolvimento, à semelhança do que se verificava nas gramáticas latinas, dedicando-lhe o autor apenas página e meia. De salientar é o facto de a retórica - disciplina tão cara ao Renascimento - ser por Fernão de Oliveira relegada, então, ao esquecimento, não obstante o gramático trate de aspectos com ela relacionáveis.

${ }^{21}$ A primeira edição é um volume de formato médio que consta de trinta e oito folhas não numeradas. $\mathrm{O}$ exemplar da Biblioteca Nacional de Lisboa tem-nas, porém, numeradas a lápis, encontrando-se distribuídas da seguinte forma: uma de frontispício; duas de dedicatória; setenta e duas de texto e uma de fecho. Uma descrição mais pormenorizada desta obra aparece em J. Pedro Machado (1938), Bibliografia filológica portuguesa. Lisboa, Centro de Estudos Filológicos, ficha $\mathrm{n}^{\circ} 465$. Sobre a história editorial desta obra, revela-se fundamental, ainda, de Amadeu Rodrigues Torres (1991), Fernão de Oliveira e a próxima edição critica da sua Grammatica da lingoagem portuguesa, Separata 26 de Actas do II Encontro sobre a História Dominicana, tomo I, vol. IV: aí, Amadeu Torres cita todas as edições até 1980 , num total de seis. 
Podemos dizer, então, que a grande proeza da inauguradora escola linguística que se criou no Portugal renascentista, especialmente representada por Fernão de Oliveira, João de Barros, Duarte Nunes de Leão e Pêro Magalhães Gândavo (cf. F. R. Gonçalves 1936: 7), foi o facto de haver conferido à língua portuguesa um estatuto nobilior - nobilior est vulgaris, já havia dito Dante Alighieri -, formalizando-se, dessa forma, o contraste entre, por um lado, a língua falada e escrita de então, o Português, e, por outro lado, a língua ainda não totalmente suplantada no domínio da escrita, o Latim. Cônscio desse contraste estava, afinal, João de Barros: «E ainda se póde crer que estas vózes, com antiguidáde, já dévem ser corrompidas, como vemos em muitos vocábulos gregos, hebraicos e latinos, que foram as três linguagens a que podemos chamár princesas do mundo, [...]. Éstas, porque perderam já a vez do uso, e tem somente a párte da escritura, leixá-lâs-emos por outras três que fázem ao propósito da nóssa, as quáes, ao presente, todalas outras preçédem, por tomárem, déstas primeiras, pártes de seus vocábulos, prinçipàlmente da latina, que foi a derradeira que teve a monarquia, cujos filhos nós somos.» (J. de Barros, 1971: 369.)

Vale dizer, entretanto, que, sob escopo dos gramáticos da época da expansão ultramarina, não estava apenas a preocupação com a valorização da língua nacional, reflectida, aliás, na divulgação do Português nos territórios recémdescobertos de então. Efectivamente, incrementar-se-ia, por consequência, o interesse pelo conhecimento e pela codificação das línguas faladas pelos povos aborígenes desses territórios.

À guisa de conclusão, não podemos deixar de salientar dois factos fulcrais.

Em primeiro lugar, tal como já sublinhado por Amadeu Torres, o processo de consciencialização da diferenciação existente entre o Latim e o Português fez-se «paulatinamente» e "com a ajuda» (A. R. Torres 1998: 47) de um conjunto importante de fontes, que integram, aliás, ou o Catálogo dos Códices Alcobacenses publicado pela Biblioteca Nacional de Lisboa, ou, por exemplo, o espólio da Bodleyan Library de Oxford (cf. A. R.Torres 1983: 635-637), a saber:

1. Papias, vocabulário e gramática (em pergaminho de letra francesa dos séculos XII-XIII) - códices allcobacenses CCCXCII-CCCXCIV/424$-426^{22}$

\footnotetext{
${ }^{22}$ A edição é, segundo P.S. Alen, dos finais do século XV.
} 
2. Derivationes, dicionário alfabético e etimológico, de Uguccione de Pisa - códice alcobacense CCCXCV/227;

3. duas Gramáticas de Prisciano: uma contendo os primeiros dezasseis livros de Institutiones grammaticae; outra contendo os dois últimos livros dessa obra;

4. Graecismus de Eberhardus Bethuniensis, de 1212 - códice 204, de 71 fólios;

5. Doctrinale de Alexandre Villa-Dei - códice 52;

6. dois glossários latinos (códice 151, de 151 fólios, século XIII), atribuídos a Alexandre Villa-Dei - códice alcobacense CCCXCIV/204;

7. glósulas ao Gaecismus, (códice 204, de 71 fólios, segunda metade do século XIV);

8. Notabilia gramaticais - códice alcobacense 79, de 1488;

9. Materies de António Martins, publicadas com a gramática de Pastrana (o Thesaurus pauperum siue Speculum puerorum), que foi impressa, em Lisboa, por Valentim Fernandes, em $1497^{23}$;

10. Normas de prosódia em harmonia com os usos de Claraval - códices alcobacenses CCLXII/37 e CCXLI/149;

11. os comentários de Petrus Rombus, que acompanham, ao modo de escólios, a gramática de Pastrana ${ }^{24}$;

12. a síntese que Petrus Rombus elaborou das Materies de António Martins, tendo sido publicada também em anexo à gramática de Pastrana ${ }^{25}$;

13. o manuscrito grammatical Digby 26 (fólios 7-7v, Col. Digby, 26, Bodleyan Library, Oxford, séc. XIV);

14. o manuscrito gramatical (fólios 76-82v), localizado no mesmo códice do manuscrito anterior, escrito, em Português, com o título "Reglas pera enformarmos os menỹnos en latin".

Em segundo lugar, os autores das primeiras descrições/normativizações do Português contribuíram significativamente para o desencadeamento e para a consequente formação, se não de parte substancial, pelo menos do alicerce do

${ }^{23}$ Antonii Martini, primi quondam huius artis Pastranae in alma Universitate Ulixbonensi praeceptoris, Materierum editio a Baculo Caecorum Breviter collecta, Lisboa, Valentim Fernandes, 1947. (BNL, inc.1427.)

${ }^{24} \mathrm{Cf}$. Compendium breve et utile siue tractatus intitulatus Thesaurus pauperum siue Speculum puerorum. Editum a magistro Iohanne de Pastrana, Lisboa, Valentim Fernandes, 1947. (BNL, inc.1425.)

${ }^{25}$ Materiarum editio ex Baculo Caecorum a Petro Rombo in Artibus Baccalario breviter collecta, Lisboa, Valentim Fernandes, 1948 (BNL, inc.1426). 
património conceptual metalinguístico, que veio a ser progressivamente maturado, a partir dos últimos anos da década de Sessenta do século XIX, por via da adopção - ainda então incipiente - de princípios metodológicos científicos, constituindo as fontes incontornáveis das correntes linguísticas que têm vindo a coexistir ou a suceder-se.

\section{BIBLIOGRAFIA REFERENCIADA}

M. S. BARRETO (1988), «Antecedentes medievais da gramática renascentista», in O Humanismo Português 1500-1600, Primeiro Simpósio Nacional, 21-25 de Outubro de 1985. Lisboa, Publicações do II Centenário da Academia das Ciências de Lisboa, p. 163-175.

J. DE BARros (1971), Gramática da língua portuguesa. (Cartinha, Gramática, Diálogo em louvor da nossa linguagem e Diálogo da viciosa vergonha), reprodução facsimilada, leitura, introdução e anotações de Maria Leonor Carvalhão Buescu. Lisboa, Publicações da Faculdade de Letras da Universidade de Lisboa.

G. L. Bursill-Hall (1994), «Linguistic Theory in the Later Middle Ages», in R. E. Asher (ed.), The Encyclopedia of Language and Linguistics, vol. 4, first edition. Oxford UK / New York USA / Seoul KOREA / Tokyo JAPAN, Pergamon Press Ltd., p. 2228, col. $2-2234$, col. 1 .

B. Colombat (2000), «La réforme de l'étude du latin à l'époque de l'humanisme», in Sylvain Auroux, E.F.K. Koerner, Hans-Josef Niederehe \& Kees Versteegh (ed.), History of the Language Sciences: an International Handbook on the Evolution of the Study of Language from the Beginnings to the Present, volume 1. Berlin / New York, Walter de Gruyter, p. 661-665.

M. A. Covington (1992), «Medieval Scholastic Grammar», in William Bright (ed.), International Encyclopedia of Linguistics, vol. 2. New York USA / Oxford UK, Oxford University Press, p. 149, col. $1-152$, col. 1.

F. R. GONÇALVES (1936), «História da filologia portuguesa», in Boletim de Filologia, 4(1-2). Lisboa.

A. Grondeux (2000), «La Grammatica positiva dans le Bas Moyen Âge», in Sylvain Auroux, E.F.K. Koerner, Hans-Josef Niederehe \& Kees Versteegh (ed.), History of the Language Sciences: an International Handbook on the Evolution of the Study of Language from the Beginnings to the Present, volume 1. Berlin / New York, Walter de Gruyter, p. 598-610.

A. M. MARTINS (1999), «Ainda "os mais antigos textos escritos em português”. Documentos de 1175 a 1252», in Isabel Hub Faria (org.), Lindley Cintra: homenagem ao Homem, ao Mestre e ao Cidadão. Lisboa, Edições Cosmos e Faculdade de Letras da Universidade de Lisboa, p. 491-534.

J. Matroso (1985a), Portugal medieval - Novas interpretações. Lisboa, Imprensa Nacional-Casa da Moeda. 
J. Matroso (1985b), Identificação de um pais - Ensaio sobre as origens de Portugal: 1096-1325, volumes I e II. Lisboa, Editorial Estampa.

J. Matroso (1995), Identificação de um pais - Ensaio sobre as origens de Portugal: 1096-1325 , volume I - Oposição, e volume II - Composição, $5^{a}$ edição, revista e actualizada. Lisboa, Editorial Estampa.

J. Matroso (21997), Religião e cultura na Idade Média portuguesa. Lisboa, Imprensa Nacional-Casa da Moeda.

R. S. Nogueira ( $\left.{ }^{3} 1933\right)$, «Prefácio», Grammatica da lingoagem portuguesa por Fernão de Oliveira. Lisboa, José Fernandes Júnior.

F. de Oliveira (2000), Gramática da linguagem portuguesa. Edição crítica, semidiplomática e anastática, organizada por Amadeu Torres \& Carlos Assunção. Lisboa, Academia das Ciências de Lisboa.

W. K. Percival (1975), «The Grammatical Tradition and the Rise of the Vernaculars», in Thomas A. Sebeok (ed.), Current Trends in Linguistics, volume 13, Historiography of Linguistics. The Hague/Paris, Mouton, p. 231-275.

W. K. Percival (1994), «Renaissance Linguistics: General Survey», in R. E. Asher (ed.), The Encyclopedia of Language and Linguistics, vol. 7, first edition. Oxford UK / New York USA / Seoul KOREA / Tokyo JAPAN, Pergamon Press Ltd., p. 3540, col. $1-3544$, col. 1 .

B. RichaRDSON (1994), «Renaissance Linguistics: Italian Tradition», in R. E. Asher (ed.), The Encyclopedia of Language and Linguistics, vol. 7, first edition. Oxford UK / New York USA / Seoul KOREA / Tokyo JAPAN, Pergamon Press Ltd., p. 3544, col. $1-3548$, col. 1 .

A. M. SÁ (1982), A Universidade de Guimarães. Paris.

A. F. SAmpalo et alii (1929), História da Literatura Portuguesa Ilustrada, vol. I. Paris, Aillaud e Bertrand.

A. D. Scaglione (1970), Ars grammatical. Haia-Paris.

R. V. M. SILVA (1989), Estruturas trecentistas: elementos para uma gramática do Português Arcaico. Lisboa, Imprensa Nacional-Casa da Moeda.

R. V. M. SILVA ( $\left.{ }^{3} 1996\right)$, Tradição gramatical e gramática tradicional. São Paulo, Contexto.

M. TAVONI (2000), "The Traditional Study of Latin at the University in the Age of Humanism», in Sylvain Auroux, E.F.K. Koerner, Hans-Josef Niederehe \& Kees Versteegh (ed.), History of the Language Sciences: an International Handbook on the Evolution of the Study of Language from the Beginnings to the Present, volume 1. Berlin / New York, Walter de Gruyter, p. 650-656.

A. R. TORRES (1983), Das fronteiras sem gramática à gramática sem fronteiras. Contributo para a gramatologia franco-portuguesa. Paris, Fondation Calouste Gulbenkian, Centre Culturel Portugais. 
A. R. TORRES (1998), «Dos códices gramaticais medievos à Gramática de Fernão de Oliveira", in Gramática e linguística: ensaios e outros estudos. Braga, Universidade Católica Portuguesa, p. 43-59.

J. L. VAsconcelos (1929), Opúsculos, vol. IV, Filologia (parte II). Coimbra, Imprensa da Universidade,

J. VAZ (1501), Commentari in grammatica, in arte discendi et componendis carminibus. Lisboa, Hermão Campos.

T. VeRdelHo (1995), As origens da gramaticografia e lexicografia latino-portuguesas. Lisboa, INIC. 